\title{
Transparent Polyisocyanurate-Polyurethane-Based Aerogels: Key Aspects on the Synthesis and Their Porous Structures
}

\author{
Beatriz Merillas,* Judith Martín-de León, Fernando Villafañe, and Miguel A. Rodríguez-Pérez
}

Cite This: ACS Appl. Polym. Mater. 2021, 3, 4607-4615

Read Online

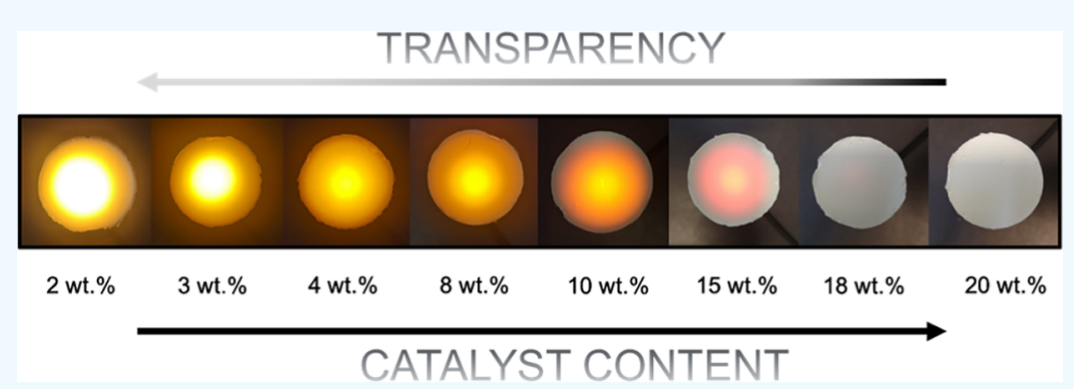

ABSTRACT: The effect of the catalyst concentration on the synthesis and textural properties of polyisocyanurate-polyurethane aerogels is analyzed. The use of different catalyst amounts allows obtaining low-density aerogels $\left(0.10-0.16 \mathrm{~g} / \mathrm{cm}^{3}\right)$ with high porosities (85-91\%). Their porous structures were analyzed by scanning electron microscopy and nitrogen adsorption-desorption isotherm. A noticeable decrease in the size of the scattering centers, particles and pores, was achieved when reducing the catalyst amount. In some samples, the small size of these features, much smaller than the wavelength of visible light, causes a bare light dispersion, leading to the first transparent polyisocyanurate-polyurethane aerogels. Light transmittance measurements at $532 \mathrm{~nm}$ have been made showing high values (ca. $76 \%$ for $1 \mathrm{~mm}$ thick samples) for the formulations with the smallest particle and pore sizes. These aerogels presenting optical transparency have many potential applications such as solar collectors, glazing systems for insulating windows, and sensors, among others.

KEYWORDS: polyisocyanurate, polyurethane, aerogels, transparent, sol-gel, particle size

\section{INTRODUCTION}

Aerogels are ultralight materials that present highly nanoporous structures with exceptional characteristics. Currently, there is a growing interest in the synthesis and characterization of these innovative materials due to their numerous applications in different fields, such as pharmaceutical and biomedical research, ${ }^{1}$ aerospace, ${ }^{2}$ building industry, ${ }^{3,4}$ etc.

Over time, much attention has been given to silica aerogels because of their low bulk density $\left(0.003-0.5 \mathrm{~g} / \mathrm{cm}^{3}\right)$, huge specific surface areas $\left(500-1200 \mathrm{~m}^{2} / \mathrm{g}\right.$ ), high porosity (more than $80 \%)$, low thermal conductivities $(0.01-0.1 \mathrm{~W} /(\mathrm{m} \mathrm{K})){ }^{5}$ and high light transmittance $(\approx 95 \%, \lambda<2.7 \mu \mathrm{m})^{6}$ among other excellent properties. ${ }^{7,8}$ Many solar-related applications have been found by combining their sunlight transmittance with their high insulating performance. ${ }^{6,9-11}$ Since their refractive index is similar to that of air, ${ }^{12}$ silica aerogels have been employed with improved efficiency for light trapping, as monoliths ${ }^{13}$ or films, ${ }^{14}$ in solar collectors. They have been also successfully used in glazing systems for insulating windows, where a sheet of silica aerogel is placed between two PMMA sheets $^{15}$ or glass panes, ${ }^{16-18}$ thus obtaining a significant reduction of heat loss and, hence, a reduction in the energy consumption while maintaining a high solar light trans- mittance. These interesting applications are only possible if the aerogel is highly transparent. Although silica is the main model of transparent aerogels, many efforts have been made in recent years to achieve similar optical properties in aerogels with organic matrices. Vivod et al. ${ }^{19}$ synthesized translucent polyimide aerogels with low thermal conductivities. Some examples involving cellulose aerogels with light transmittance properties can be found in the literature. ${ }^{20,21}$ For instance, flexible transparent cellulose aerogels having excellent mechanical properties were fabricated by $\mathrm{Mi}$ et al. ${ }^{22}$ through a dissolution-regeneration method. Kobayashi et al. ${ }^{23}$ reported a three-dimensional (3D) nanofiber skeleton of liquidcrystalline nanocellulose combining a controlled mechanical toughness, transparency, and insulating performance. Nakanishi et al. ${ }^{24}$ reported the synthesis of colorless transparent melamine-formaldehyde (MF) aerogels showing high light

Received: June 15, 2021

Accepted: August 10, 2021

Published: September 1, 2021 
transmittance values. Aldehyde-free, chitosan aerogels were presented by Takeshita et al., ${ }^{25}$ showing a relationship between the initial urea concentration and their final optical properties. The combination of the exceptional properties of these organic aerogels in one single material opens the way to a wide range of potential applications in which the current materials used (including silica aerogel) could be replaced. For instance, the building sector is susceptible to significant energy efficiency improvements through enhanced-performance insulating transparent materials, where aerogels could play the main role. ${ }^{26}$

The widespread use of polyurethane (PU) foams as thermal insulators in walls and roofs is well known due to their costeffectiveness and insulating capacity. Nevertheless, their thermal insulating performance, which covers a range from 20 to $30 \mathrm{~mW} /(\mathrm{m} \mathrm{K}),{ }^{27}$ presents room for improvement. Polyurethane aerogels may satisfy the growing demands in this field, ${ }^{28}$ fulfilling the lower thermal conductivity requirements while keeping the excellent properties of this polymeric matrix and its low cost. The first polyurethane and polyisocyanurate (PIR) aerogels were synthesized in the 1990s by Biesmans et $\mathrm{al}^{29,30}$ reaching a thermal conductivity value of $22 \mathrm{~mW} /(\mathrm{m} \mathrm{K})$ for a density of $150 \mathrm{~kg} / \mathrm{m}^{3}$. Since then, some attempts to enhance their insulating performance and mechanical properties have been carried out. Rigacci et al. ${ }^{31}$ synthesized polyurethane gels by employing two polyols of different functionality and changing the solubility of the reaction media. Thermal conductivity measurements were performed, and the effect of solubility in this property was evaluated, reaching values between 22 and $24 \mathrm{~mW} /(\mathrm{m} \mathrm{K})$ at atmospheric pressure and room temperature. Diascorn et al. ${ }^{32}$ changed the catalyst concentration in the polyurethane aerogel formulations to study the influence of this parameter on the final properties. They found that an "optimum" density of $0.18 \mathrm{~g} / \mathrm{cm}^{3}$ led to a minimal thermal conductivity value of $17 \mathrm{~mW} /(\mathrm{m} \mathrm{K})$. Chidambareswarapattar et al. ${ }^{33}$ used different isocyanates and polyols for the synthesis of PU aerogels, ranging from flexible to rigid. They obtained a relationship between the functional group density of the monomer and the structure-properties of the final aerogels. Zhu et al. ${ }^{34}$ carried out a study based on the influence of the gelation solvent on the final density, thermal conductivity, and microstructures of PUR-PIR aerogels. The employed solvent was found to have a dramatic effect on the aerogel properties being a parameter to select carefully. To conclude, the literature focused on PU-based aerogels is scarce, and, as far as the authors know, the aerogels reported up to now do not present transparency. Therefore, applications of the materials so far described would be limited due to their lack of transparency.

Herein, we report the synthesis of the first transparent polyisocyanurate-polyurethane-based aerogels. The effect of different catalyst contents on the nanoporous structure and on light transmittance has been analyzed in detail. This procedure allows a systematic approach to obtaining PIR-PUR aerogels from opaque to transparent materials with tunable properties, such as bulk density, controlled particle size, pore size, and optical properties. The production of these materials would allow the substitution of transparent silica aerogels for a much more cost-effective system in applications such as glazing systems or solar collector covers where silica aerogels are already employed. ${ }^{18,35,36}$ In addition, the exciting combination of properties of the materials produced in this paper could lead to applications not still imagined.

\section{EXPERIMENTAL SECTION}

2.1. Materials. Tetrahydrofurane extra pure (purity > 99.5\%) stabilized with $250 \mathrm{ppm}$ butylated hydroxytoluene (BHT), acetonitrile high-performance liquid chromatography (HPLC) grade (purity $>99.9 \%$ ), dimethyl sulfoxide synthesis grade (purity $>99.5 \%$ ), and acetone synthesis grade (purity $>99.5 \%$ ) were supplied by Scharlab, S. L. Pentaerythritol (purity > 98\%) with a density of $\rho=1.396 \mathrm{~g} / \mathrm{cm}^{3}$ (at $20{ }^{\circ} \mathrm{C}$ ) was provided by Alfa Aesar.

Polymeric methylene diphenyl diisocyanate (p-MDI) corresponding to the formulation 4,4'-diphenylmethane diisocyanate, IsoPMDI $92140\left(\rho=1.23 \mathrm{~g} / \mathrm{cm}^{3}\right.$ at $\left.25{ }^{\circ} \mathrm{C}\right)$, was purchased from BASF Polyurethane. Potassium octoate dissolved in ethylene glycol commercialized as KOSMOS 75 MEG was provided by Evonik. ${ }^{41}$

2.2. Synthesis of Gels. PIR-PUR gels were synthesized through a polycondensation reaction between isocyanate and polyol that occurs in solution, forming a hyperbranched solid network (Figure S1). Pentaerythritol $(100 \mathrm{~g} / \mathrm{L})$ was added to the $\mathrm{p}-\mathrm{MDI}$ solution $(44 \mathrm{~g} / \mathrm{L})$, keeping a relationship npolyol $/$ nisocyanate $=0.43$. Then, the corresponding amount $[1-20 \mathrm{wt} \%]$ of a potassium catalyst solution $(70 \mathrm{~g} / \mathrm{L})$ was added, and the initial sol was stirred at $500 \mathrm{rpm}$ for $20 \mathrm{~s}$ at room temperature and then poured into a polypropylene container. The weight percentage of the catalyst is calculated from the total mass of both precursors, polyol, and isocyanate. Once gels were obtained, they were covered with acetonitrile for $24 \mathrm{~h}$ at room temperature to allow aging. The gels thus obtained were washed twice with acetonitrile every $24 \mathrm{~h}$ to remove the nonreacted chemicals. Synthesis details can be found in Supporting Information Section 1. Regarding the molar relationship between the two main components, an excess of $-\mathrm{NCO}$ groups is always present. Therefore, the urethane bond formation by the reaction with the polyol is accompanied by the formation of secondary products during the polymerization step, such as allophanates and isocyanurates through the isocyanate trimerization reaction. ${ }^{40}$ To ensure the completion of the reaction, a cyclotrimerization catalyst was chosen for the process. ${ }^{41}$ Finally, gels were supercritically dried as described in Supporting Information Section 2.

2.3. Aerogel Characterization Methods. 2.3.1. Gelation Time. Gel time is the time required to obtain a material which does not flow anymore. The initial sol presents a transparent yellowish appearance and, when the polymerization reaction takes place, it turns out to be transparent bluish in the case of a less amount of the catalyst or to opaque white for the highest concentrations. As determining the specific gel time visually is rather difficult, especially for the lower catalyst amounts, the container is carefully tilted, so gel time is fixed as that moment when the gel is not deformed by tilting.

2.3.2. Shrinkage. The linear shrinkage percentage is determined between the gel formation and the final dried aerogel. It is calculated by eq 1

$$
\% \text { linear shrinkage }=\left(1-d / d_{0}\right) \times 100
$$

where $d_{0}$ and $d$ are the diameters measured prior and after the drying process.

2.3.3. Density. Geometrical density $\rho$ was measured as described by ASTM D1622/ D1622M-14 ${ }^{37}$ by measuring the mass with an AT261 MettlerToledo balance and the geometric volume with a caliper.

Solid density or skeletal density $\rho_{\mathrm{s}}$ was determined through helium pycnometry with an AccuPyc II 1340, Micromeritics. To guarantee the replacement of the gas inside the aerogel pores, 200 purges with helium were made. A pressure of $0.13 \mathrm{MPa}$ was employed for the measurements.

The solid fraction of the aerogels is described by the relative density as the fraction between geometrical density $(\rho)$ and skeleton density $\left(\rho_{\mathrm{s}}\right)$ (eq 2 ).

$$
\rho_{\mathrm{r}}=\frac{\rho}{\rho_{\mathrm{s}}}
$$


2.3.4. Porous Structure. 2.3.4.1. Porosity. The apparent porosity (П), which accounts for the volume fraction of the gas phase, is calculated from the relative density $\rho_{\mathrm{r}}$ (eq 3 ).

$$
\Pi=\left(1-\rho_{\mathrm{r}}\right) \times 100
$$

2.3.4.2. Surface Area (BET). Nitrogen adsorption measurements were carried out at $-196{ }^{\circ} \mathrm{C}$ with a Micromeritics ASAP 2020 instrument at the University of Malaga (Spain). Samples were first degassed under high vacuum at $50{ }^{\circ} \mathrm{C}$ for $24 \mathrm{~h}$. Specific surface areas $\left(S_{\mathrm{BET}}\right)$ were obtained by the Brunauer-Emmett-Teller (BET) method $^{38}$ in the pressure range $P / P_{0} 0.05-0.30$.

2.3.4.3. Pore Volume and Pore Size. Pore size distributions were determined by the Barrett-Joyner-Halenda (BJH) method ${ }^{38}$ through the desorption branch of the $\mathrm{N}_{2}$-sorption isotherm, assuming that pores have a cylindrical shape. Since macroporosity could not be determined by this technique owing to capillary condensation, the average pore diameter was estimated by taking into account the pore volume as the free aerogel volume. Therefore, the total pore volume per gram $\left(V_{\mathrm{p}}\right)$ was estimated through the difference between the total volume $(1 / \rho)$ and the solid phase volume $\left(1 / \rho_{\mathrm{s}}\right)$ for a unitary mass, as defined by eq 4 .

$$
V_{\mathrm{p}}=\frac{1}{\rho}-\frac{1}{\rho_{\mathrm{S}}}
$$

This total pore volume and the specific surface area obtained by BET were employed to determine the average pore size $\left(\varphi_{\mathrm{p}}\right)$ by eq 5

$$
\Phi_{\mathrm{p}}=\frac{4 V_{\mathrm{p}}}{S_{\mathrm{BET}}}
$$

2.3.4.4. Particle Size. The aerogel's structure was characterized using an ESEM Scanning Electron Microscope (QUANTA 200 FEG, Hillsboro, OR). Prior to the visualization, samples were cut with a metal blade and then coated with a layer $(5-10 \mathrm{~nm}$ thickness) of iridium using a sputter coater (EMITECH K575X Sputter Coater). This metal was used to prevent the formation of the aggregates that occurs when gold is employed.

Once micrographs were obtained, particle size $(d)$ was measured through a software-based on Image $\mathrm{J} / \mathrm{FIJI},{ }^{39}$ as shown in Figure 1.
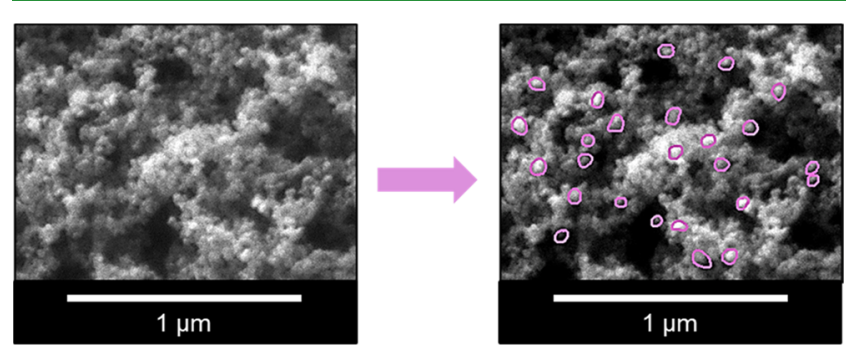

Figure 1. Particle contour drawing using Image J/FIJI to estimate the particle size.

More than 50 individual particles were used to estimate the average diameter for each sample. The normalized standard deviation (NSD) was calculated to evaluate the homogeneity of each particle size as the standard deviation of the particle distribution divided by the average particle diameter $(\mathrm{SD} / d)$.

2.3.4.5. Transmittance Measurements. To determine the transmittance of the aerogels, a device consisting of a green laser was used as a light source. The corresponding wavelength and intensity were $532 \mathrm{~nm}$ and $22 \mathrm{~mW}$, respectively. The light detector was formed by a photodiode joined to an integrating sphere with a $12.5 \mathrm{~mm}$ window (PRW0505, Gigahertz-Optik), which was connected to a photometer (X94, Gigahertz- Optik). The laser-detector distance was fixed at 133 $\mathrm{mm}$. Transmittance is calculated as the ratio between the transmitted intensity that reaches the detector $(I)$ and the incident intensity without the sample $\left(I_{0}\right)$.
Aerogels were placed in contact with the window of the integrating sphere to collect the maximum intensity. Due to the difficulty of obtaining samples with the same thickness, measurements were made for the final aerogels having different thicknesses and a correction was employed to compare transmittance values at equivalent thickness. The relationship between the transmittances for two different thicknesses is described by the following equation

$$
T=T_{0}^{L / L_{0}}
$$

\section{RESULTS AND DISCUSSION}

Aerogels were fabricated through a sol-gel process, as detailed in Figure 2a. The Fourier transform infrared (FT-IR) spectra of the final aerogels display the characteristic IR peaks for polyurethane and polyisocyanurate (Figure S3): a broad absorption band in the $3600-3200 \mathrm{~cm}^{-1}$ region assigned to $\mathrm{N}-\mathrm{H}$ stretching, ${ }^{42}$ the urethane and urea carbonyl stretching absorptions at 1709 and $1597 \mathrm{~cm}^{-1}$, respectively, the $\mathrm{N}-\mathrm{H}$ bending coupled to the $\mathrm{C}-\mathrm{N}$ stretching is detected at ca. 1513 $\mathrm{cm}^{-1}$, the isocyanurate carbon-nitrogen stretching is present at $1412 \mathrm{~cm}^{-1}$, 33 and the $\mathrm{C}-\mathrm{N}$ stretch can be observed at ca. $1217 \mathrm{~cm}^{-1}$.

During the gelation step, the liquid yellowish sols start to react during a gel time, which is that required to obtain a jellylike appearance, and it does not flow anymore. Gel times range from $90 \mathrm{~min}$ (for the sample with $1 \mathrm{wt} \%$ catalyst) to $40 \mathrm{~s}$ (for the sample with 20 wt \% catalyst), as shown in Figure $2 \mathrm{~b}$. The PIR-PUR aerogel reaction kinetics is controlled by the amount of the catalyst added to the initial sol, which regulates a faster or slower polycondensation reaction. The optical properties of the gels are notably different depending on the amount of the catalyst. Gels are opaque (higher amounts) or transparent (lower amounts), as displayed in Figure $2 \mathrm{c}$,d. These optical differences must be related to the particle size of the primary particles formed during the sol-gel process. ${ }^{29}$ Opaque gels are formed by a $3 \mathrm{D}$ network where the particles size is large enough to interact with visible light through scattering mechanisms (20 and $18 \mathrm{wt} \%)$. On the contrary, the transparent gels should consist of small primary particles, which do not present a strong interaction with visible light (mainly Rayleigh scattering) so they mainly transmit light. For intermediate catalyst concentrations (10 and $15 \mathrm{wt} \%$ ), gels can be considered translucent. The catalyst concentration affects different factors apart from reaction kinetics, such as bulk densities and shrinkages, as well as the porous structure of the final aerogels. The characterization techniques to analyze these features are described in the Supporting Information (section 5).

Bulk and relative densities are summarized in Table 1. Bulk densities are very low for all of the aerogel samples, comprising values between 165 and $101 \mathrm{~kg} / \mathrm{m}^{3}$. The data show a strong inverse relationship between bulk density $\left(\rho_{\mathrm{B}}\right)$ and the amount of the catalyst. The maximum value of density is obtained for a catalyst amount of $3 \mathrm{wt} \%$, and from that point, the bulk density notably decreases when a higher amount of the catalyst is added. For the lowest values of the catalyst, 1 and $2 \mathrm{wt} \%$, a reduction of density can be observed, which might be related to an incomplete chemical reaction for these lowest catalyst ratios. The density data are supported by the linear shrinkage values (Table 1), which clearly show the same tendency since the shrinkage increases with higher densification of the skeletal structure. The maximum total linear shrinkage is $26.46 \%$. The average solid density $\left(\rho_{\mathrm{S}}\right)$ was calculated by helium 
a

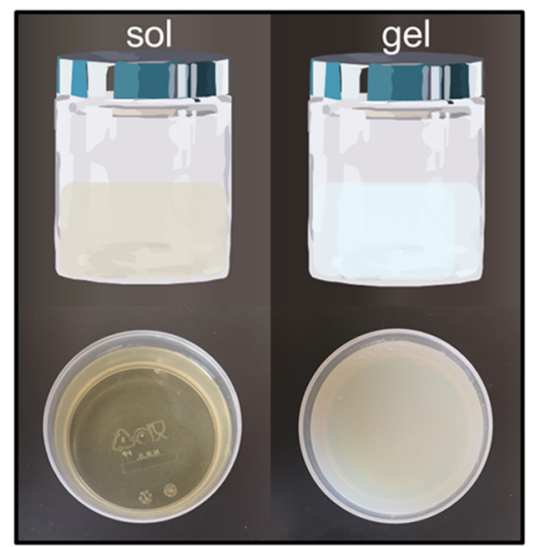

$b$

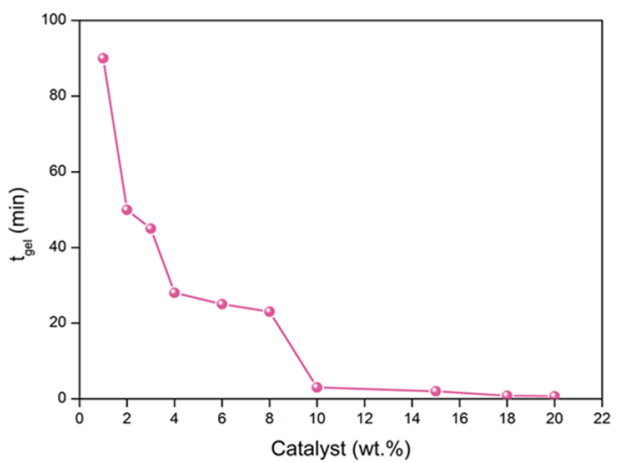

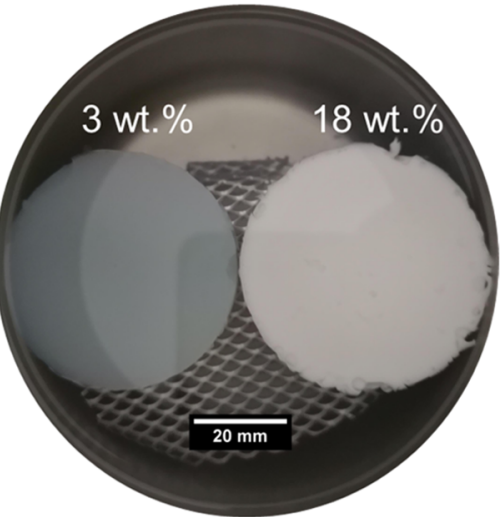

d

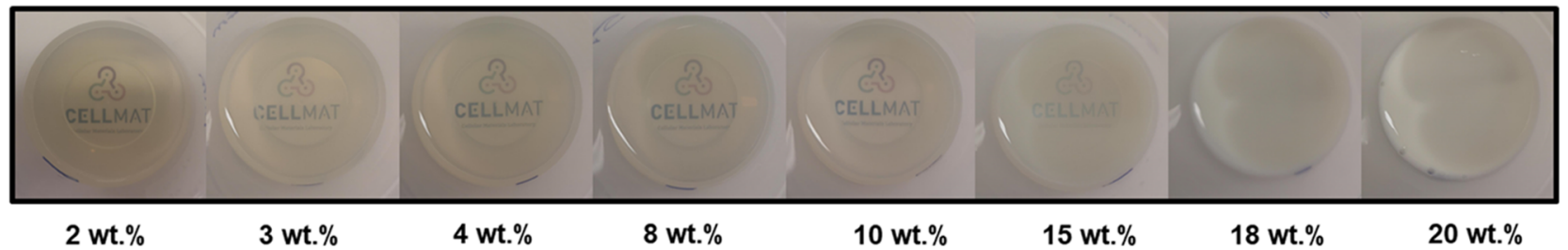

Figure 2. PIR-PUR gels. (a) Sol and gel pictures for one of the samples under study. (b) Measured gel times for the different catalyst amounts (wt \%). (c) Photograph of two of the gels, containing different amounts of the catalyst (3 and $18 \mathrm{wt} \%$ ), inside the drying reactor. (d) Gel appearance for each catalyst percentage (wt \%). CellMat logo used with permission of the Cellular Materials Laboratory (CellMat).

Table 1. Properties and Structural Parameters of the Final Aerogels ${ }^{a}$

\begin{tabular}{|c|c|c|c|c|c|c|c|c|c|c|}
\hline $\begin{array}{l}\text { catalyst } \\
\text { wt } \%\end{array}$ & $\begin{array}{c}\rho_{\mathrm{B}} \\
\left(\mathrm{g} / \mathrm{cm}^{3}\right)\end{array}$ & $\rho_{\mathrm{R}}$ & $\begin{array}{c}\text { linear shrinkage } \\
(\%)\end{array}$ & $\Pi(\%)$ & $\begin{array}{c}S_{\mathrm{BET}} \\
\left(\mathrm{m}^{2} / \mathrm{g}\right)\end{array}$ & $\varphi_{\mathrm{p}}(\mathrm{nm}) \mathrm{BJH}$ & $\begin{array}{c}V_{\mathrm{p}} \\
\left(\mathrm{cm}^{3} / \mathrm{g}\right)\end{array}$ & $\begin{array}{c}\text { mean pore size } \varphi_{\text {MEAN }} \\
(\mathrm{nm})\end{array}$ & $d(\mathrm{~nm})$ & $\mathrm{SD} / d$ \\
\hline 1 & 0.142 & 0.12 & 21.22 & 87.86 & 289.82 & 6.74 & 6.18 & 85.24 & 25.40 & 0.25 \\
\hline 2 & 0.141 & 0.12 & 19.48 & 87.99 & 294.11 & 6.79 & 6.25 & 85.04 & 24.63 & 0.22 \\
\hline 3 & 0.165 & 0.14 & 22.92 & 85.89 & 288.15 & 6.67 & 5.19 & 72.08 & 23.04 & 0.26 \\
\hline 4 & 0.154 & 0.13 & 26.46 & 86.84 & 242.09 & 6.95 & 5.63 & 93.05 & 25.58 & 0.25 \\
\hline 6 & 0.141 & 0.12 & 22.92 & 87.97 & 274.12 & 6.98 & 6.24 & 91.09 & 31.96 & 0.22 \\
\hline 8 & 0.131 & 0.11 & 22.53 & 88.84 & 197.10 & 7.12 & 6.79 & 137.85 & 34.12 & 0.23 \\
\hline 10 & 0.114 & 0.10 & 18.44 & 90.23 & 224.28 & 6.88 & 7.88 & 140.57 & 32.55 & 0.21 \\
\hline 15 & 0.101 & 0.09 & 17.09 & 91.38 & 145.21 & 7.08 & 9.04 & 249.14 & 45.67 & 0.27 \\
\hline 18 & 0.102 & 0.09 & 16.46 & 91.31 & 49.70 & 6.72 & 8.97 & 721.94 & 78.60 & 0.20 \\
\hline 20 & 0.102 & 0.09 & 17.53 & 91.27 & 64.67 & 6.92 & 8.92 & 551.94 & 81.76 & 0.23 \\
\hline
\end{tabular}

${ }^{a}$ Bulk density $\left(\rho_{\mathrm{B}}\right)$ measured as geometric density, relative density $\left(\rho_{\mathrm{R}}\right)$ obtained as $\rho_{\mathrm{R}}=\rho_{\mathrm{B}} / \rho_{\mathrm{s}}$, linear shrinkage $=\left(1-d / d_{0}\right) \times 100$, where $d_{0}$ and $\mathrm{d}$ are the diameters measured prior and after the drying process, porosity $\Pi=\left(1-\rho_{\mathrm{R}}\right) \times 100, S_{\mathrm{BET}}$ obtained by the nitrogen sorption technique, pore size $\left(\Phi_{\mathrm{P}}\right)$ obtained by the BJH model, total pore volume per gram $V_{\mathrm{p}}=\left(1 / \rho_{\mathrm{B}}\right)-\left(1 / \rho_{\mathrm{s}}\right)$, mean pore size $\left(\Phi_{\mathrm{MEAN}}\right)$ calculated as $\Phi_{\mathrm{MEAN}}=(4 \times$ $\left.V_{\mathrm{p}}\right) / S_{\mathrm{BET}}, d$ is the particle diameter obtained for more than 50 individual particles, and the $\mathrm{SD} / d$ is the normalized standard deviation of the particle diameter.

pycnometry, obtaining an average value of $1.17 \pm 0.03 \mathrm{~g} / \mathrm{cm}^{3}$. Therefore, this value, which is similar to the values obtained in previous studies with PU aerogels, ${ }^{44}$ was employed as the skeletal density of the aerogels herein obtained. Taking this data into account, relative density $\left(\rho_{\mathrm{r}}\right)$ ranges from 0.09 , for samples with a high catalyst amount, to 0.12 for the lower concentrations.

The porous structure of aerogels plays the main role in their final properties. Porosity values (П) can be found in Table 1 . As expected, this parameter reaches higher values for samples with lower densities, showing a maximum value of $91 \%$ for the samples containing 15,18 , and 20 wt $\%$ catalyst. This could be explained by the interparticle voids, which give rise to larger porosities when they are more numerous and, therefore, densities are lower. Porosity values for all of the produced samples are high, the minimum value being $85.89 \%$ for the sample with the greatest density (3 wt \%).

The scanning electron micrographs reveal a pearl-necklace structure for the PIR-PUR aerogels (Figure 3) formed by interconnected particles that has a strong dependence on the catalyst content. Particle size was measured from these pictures by means of a software-based on Image J/FIJI. ${ }^{39}$ A clear trend can be observed with the amount of the catalyst: when the catalyst concentration is reduced, particle sizes are strongly reduced reaching values as low as $23 \mathrm{~nm}$.

Particle diameter values $(d)$ are gathered in Figure $4 a$, where three different regions can be observed: The first one comprises the samples with lower catalyst amounts $(1,2,3$, and $4 \mathrm{wt} \%$ ), which present particle size values below $30 \mathrm{~nm}$. The second region is formed by samples with 6,8 , and $10 \mathrm{wt}$ $\%$, with a particle size below $35 \mathrm{~nm}$, and the third region is 

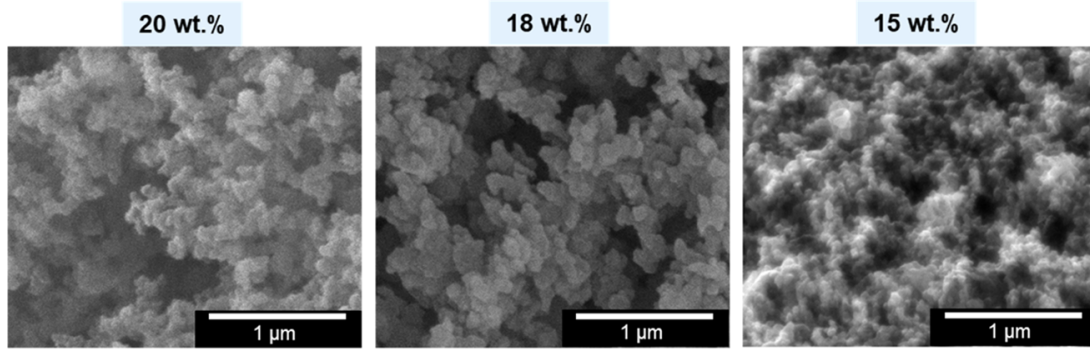

10 wt. $\%$

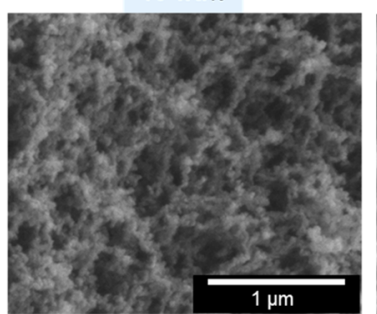

8 wt. $\%$
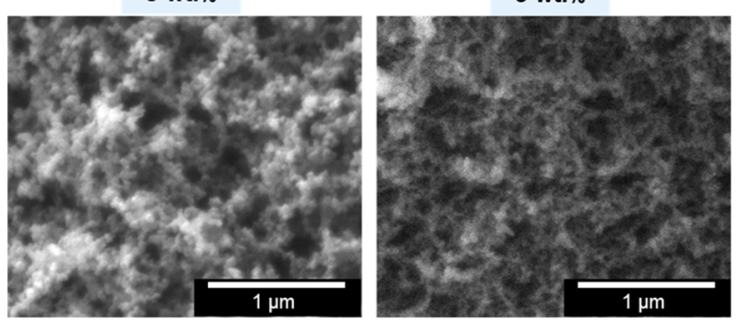
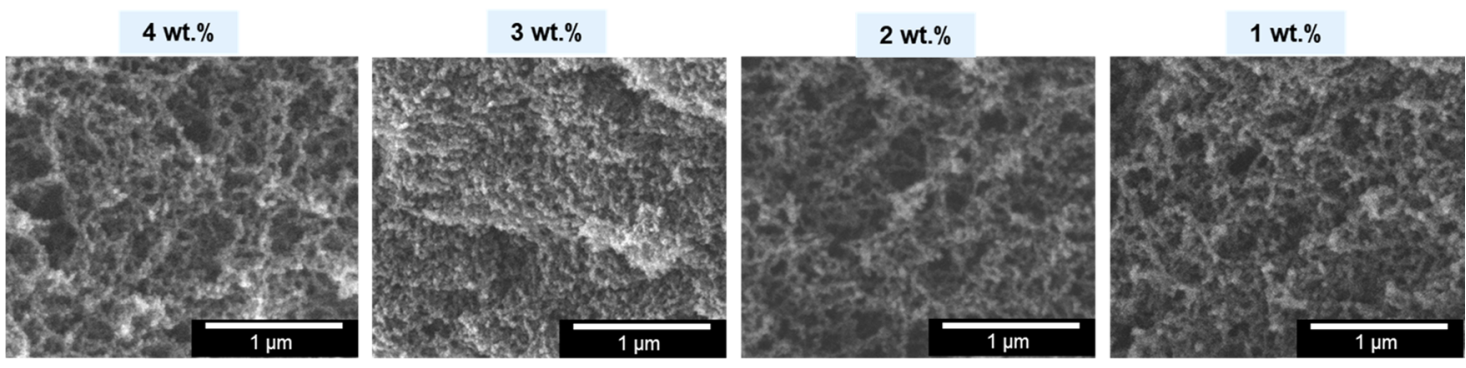

Figure 3. Representative scanning electron micrographs for each aerogel formulation.

observed for samples 15,18 , and 20 wt $\%$, which present the highest particle size values, higher than $40 \mathrm{~nm}$. Regarding the normalized particle size distribution $(\mathrm{SD} / d)$ included in Table 1 , it is similar for all of the aerogels, the values being very low, in the range between 0.21 and 0.27 . These results indicate that the particle size distribution is homogeneous.

Porous structures were characterized by the nitrogen sorption technique. The obtained isotherms correspond mainly to type IV isotherms according to the IUPAC classification, ${ }^{45}$ typical of mesoporous adsorbents $(2-50 \mathrm{~nm}$ ) (Figure $4 \mathrm{~b}$ ). However, as the catalyst amount increases, the isotherms tend to resemble a type II-like isotherm, accounting for the presence of macropores. Figure $4 \mathrm{~b}$ depicts three nitrogen sorption isotherms for a low catalyst content ( $2 \mathrm{wt} \%)$, adsorbing a large amount of nitrogen, an intermediate content (10 wt \%), and the highest content (20 wt \%), which shows a narrower hysteresis and a significantly smaller quantity absorbed. The $S_{\mathrm{BET}}$ areas are plotted in Figure $4 \mathrm{c}$, demonstrating the significant difference between samples. It is evident that samples exhibit a sharp decrease in the surface areas (BET) when the gelation reaction is faster (Table 1). The aerogels with the smallest amounts of the catalyst show larger specific surface areas, 289.81, 294.11, and $288.15 \mathrm{~m}^{2} / \mathrm{g}$ for 1,2 , and 3 wt \%, respectively, whereas the aerogels with the highest catalyst concentrations present surface area values below 100 $\mathrm{m}^{2} / \mathrm{g}$. These results are in agreement with particle size measurements from the previous section, so aerogels with larger particles show a lower $S_{\mathrm{BET}}$.

Regarding the pore size distribution, Figure $4 \mathrm{~d}$ shows that all of the samples present pores in the $5-25 \mathrm{~nm}$ range. However, pores above $25 \mathrm{~nm}$ cannot be determined for these aerogels by the sorption technique due to the capillary condensation process or compression of the aerogels when nitrogen condenses. ${ }^{46}$ To overcome the limitations of these measurements, mean pore size was estimated by taking into account the total pore volume obtained through geometric and solid densities (Table 1). Since SEM micrographs confirm the existence of bigger pores, this estimation is useful to obtain the mean pore size trend. Table 1 shows the mean pore values, which are smaller than $100 \mathrm{~nm}$ for samples with a catalyst amount below 8 wt \%. For higher contents, these values start to increase, reaching higher pore sizes $(500-700 \mathrm{~nm})$, which contribute to reducing the optical transmission of these samples. For low contents of the catalyst, transparent aerogels were obtained. To determine the optical transparency, transmittance measurements were carried out employing a green laser $(532 \mathrm{~nm})$ as a light source (Supporting Information).

As indicated above, the particle diameters obtained for the aerogels of this work (Figure 4a) display three different groups. When particles are smaller than $30 \mathrm{~nm}$ (samples 1, 2, 3, and 4 wt \%), light interaction would be minimized, these aerogels being those which show the highest transmittance. Additionally, a reduction of the particle size contributes to more effective packaging and thus to smaller pores. Therefore, transmittance follows a clear trend with the catalyst concentration, as shown in Figure 5a. The aerogel with the lowest wt. \% reaches the highest transmittance value of $76 \%$ for a sample with $1 \mathrm{~mm}$ of thickness. This transmittance value is similar to that obtained for other organic aerogels at the same wavelength. For instance, chitosan aerogels with a thickness of $1 \mathrm{~mm}$ showed $73 \%{ }^{47}$ and $83 \%{ }^{25}$ maximum transmittances. In the case of cellulose aerogels, $70 \%$ transmittances were reached $^{22,48}$ for the same thickness at $500 \mathrm{~nm}$. The 
a

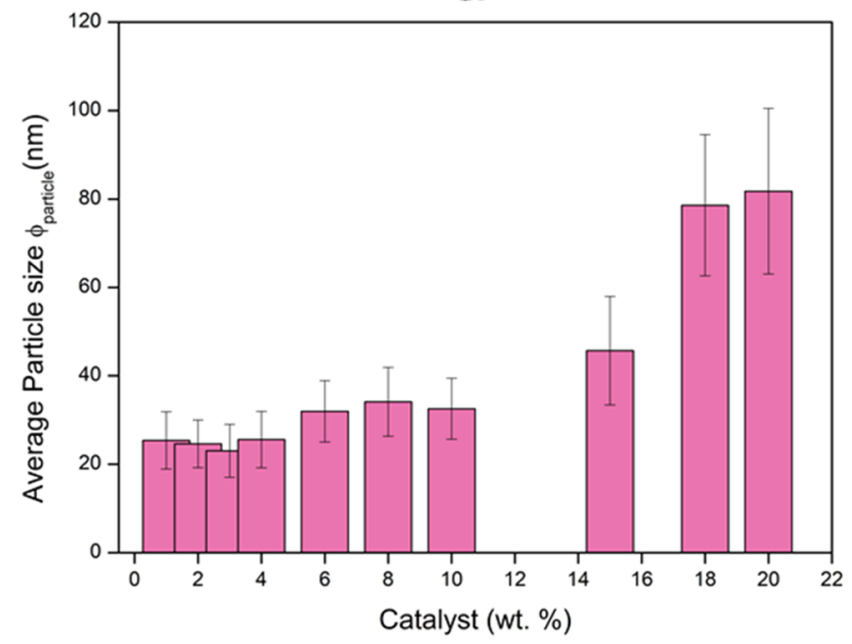

C

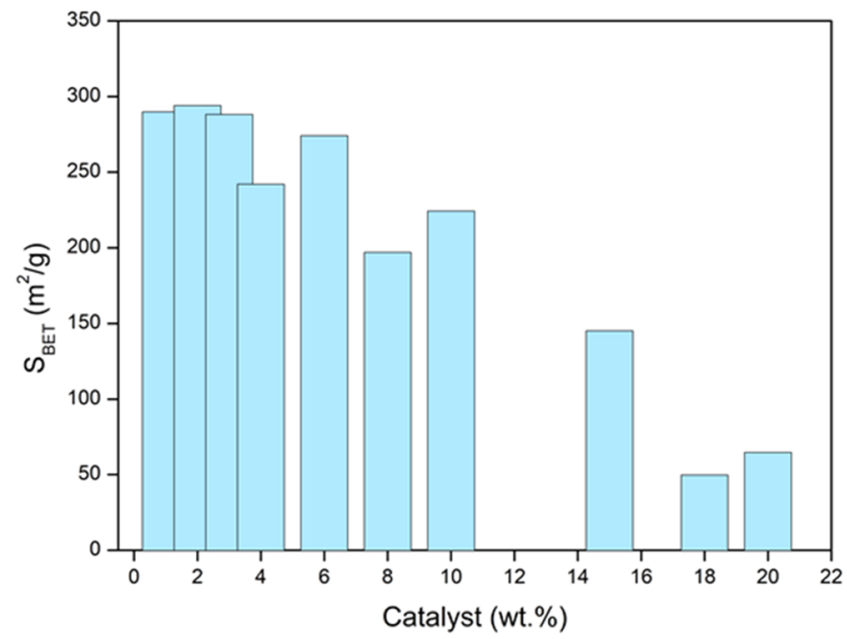

b

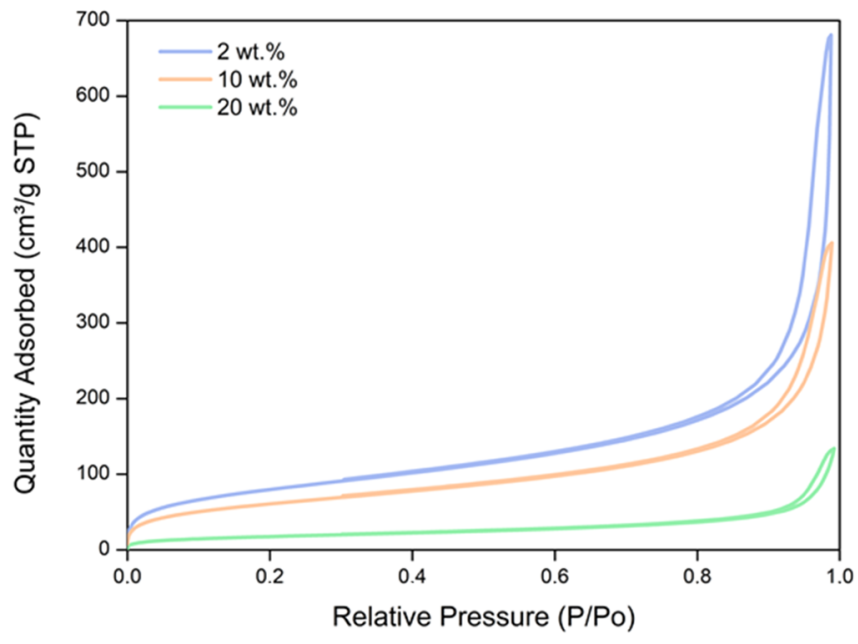

d

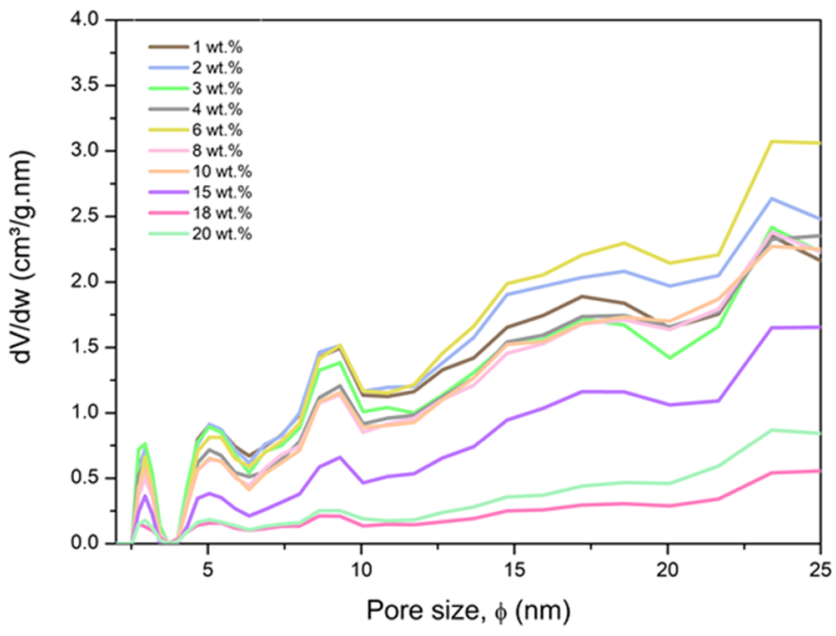

Figure 4. Average particle size measured by SEM micrographs (a), nitrogen adsorption/desorption isotherms (b), specific surface area (c), and calculated BJH graphs for the pore size distributions (d) for the aerogel samples with different catalyst amounts (wt \%).

transmittance slightly decreases when the catalyst concentration increases. For samples with 2, 3, and $4 \mathrm{wt} \%$ (Figure $5 \mathrm{~b}$, samples 1,2 , and 3 ), the transmittance values are above $60 \%$. In the second group $(6,8$. and $10 \mathrm{wt} \%)$, as the particle size increases, transparency is progressively reduced (values between 42 and 47\%). The sample with 15 wt \% presents the limit of the particle size $(45.67 \pm 12.26 \mathrm{~nm})$ to show slight transparency (33\% transmittance). For the last two samples, particle diameters are above $50 \mathrm{~nm}$, and the materials $1 \mathrm{~mm}$ in thickness are opaque (Figure $5 b$, sample 5).

The relationships between transparency and the rest of properties studied deserve a deeper insight. Aerogel's transparency mainly depends on three parameters: density, particle size, and pore size. ${ }^{49}$ As discussed before, density increases when the catalyst amount decreases, mainly due to strong shrinkages. Although the porosity is slightly reduced with this shrinkage, it also contributes to diminishing the mean pore size. For this reason, samples with a low wt \% catalyst show the highest transmittances. Both particles and pores forming the aerogel 3D network play a main role in the optical properties since light scattering mechanisms are related to the presence of these features and are stronger when these structures are large. ${ }^{50}$ These scatters should present an average size below a tenth of the visible wavelength $(400-700 \mathrm{~nm})$ where the scattered light is mainly due to the Rayleigh mechanism ${ }^{51,52}$ to have a small interaction with visible light, providing, in this case, transparent materials.

\section{CONCLUSIONS}

Herein, we describe the fabrication of transparent PIR-PUR aerogels for the first time. This transparency can be controlled by the porous structure, which is tunable through the reaction kinetics. Thus, a clear relationship is found between the catalyst concentration and different parameters. Bulk density and linear shrinkage decrease when the catalyst amount increases. Particle diameters are larger for high catalyst contents (above $50 \mathrm{~nm}$ for 18 and $20 \mathrm{wt} \%$ ), reducing the specific average surface area below $100 \mathrm{~m}^{2} / \mathrm{g}$ and increasing the pore size of these aerogels, which display a reduction in the final transparency reaching opacity. In contrast, the diameters of the particles forming their solid network in aerogels with lower amounts of the catalyst are below a tenth of the 
a

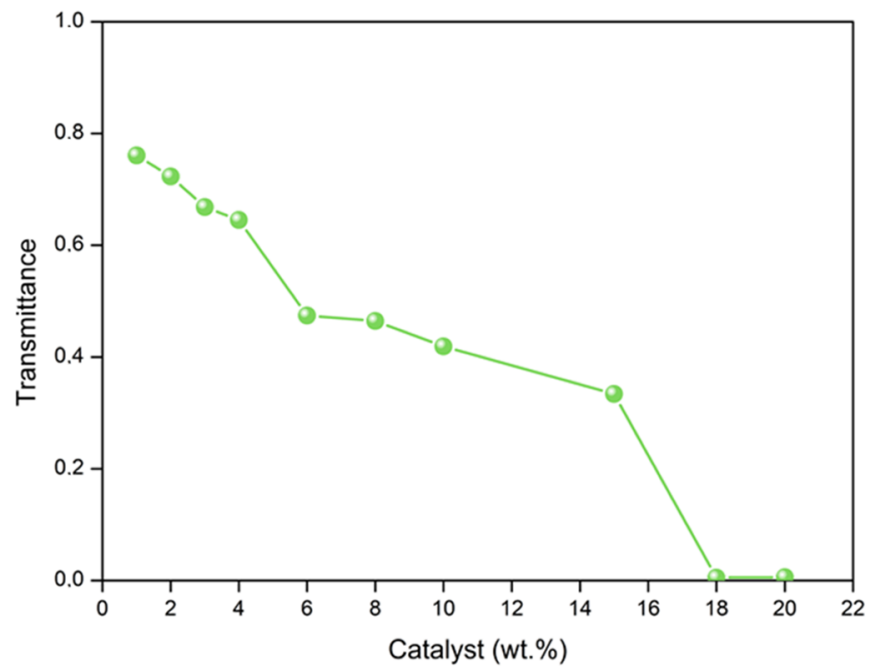

b

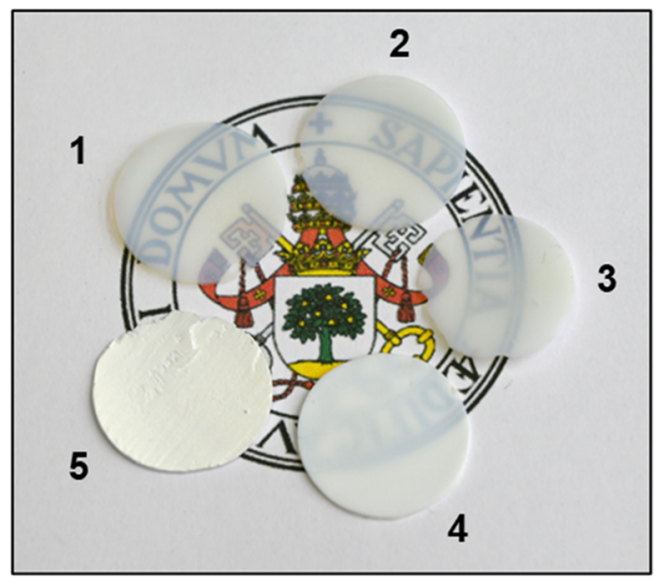

Figure 5. Aerogel's transparency. (a) Transmittance as a function of the catalyst content for $1 \mathrm{~mm}$ thick aerogels. (b) Photograph of final aerogels $(1: 2,2: 3,3: 4,4: 10,5: 20 \mathrm{wt} \%)$ of ca. $1 \mathrm{~mm}$ thickness. University of Valladolid emblem used with permission of the Rectorate of the Univesrity of Valladolid.

wavelength of the visible light $(40 \mathrm{~nm})$. This fact, combined with the small pore sizes that these aerogels show, allows them to be highly transparent. Transmittance measurements were carried out at $532 \mathrm{~nm}$ reaching a $76 \%$ transmittance for $1 \mathrm{~mm}$ thick aerogels. The synthesis of PUR-PIR aerogels presenting these optical transparency values together with the expected low thermal conductivities opens a wide range of possible solar-related applications such as aerogel insulating windows or solar collectors and also glazing systems. Detailed studies of the optical properties, thermal conductivity, and mechanical properties of these novel aerogels are in progress.

\section{ASSOCIATED CONTENT}

\section{(s) Supporting Information}

The Supporting Information is available free of charge at https://pubs.acs.org/doi/10.1021/acsapm.1c00712.

Gel synthesis, supercritical drying details, and FT-IR spectra (PDF)

\section{AUTHOR INFORMATION}

\section{Corresponding Author}

Beatriz Merillas - Cellular Materials Laboratory (CellMat), Condensed Matter Physics Department, Faculty of Science, University of Valladolid, 47011 Valladolid, Spain; 다이.org/0000-0003-2995-6412; Email: b.merillas@ fmc.uva.es

\section{Authors}

Judith Martín-de León - Cellular Materials Laboratory (CellMat), Condensed Matter Physics Department, Faculty of Science, University of Valladolid, 47011 Valladolid, Spain; (1) orcid.org/0000-0002-6567-1783

Fernando Villafañe - Cellular Materials Laboratory (CellMat), Condensed Matter Physics Department, Faculty of Science, University of Valladolid, 47011 Valladolid, Spain; Present Address: GIR MIOMeT-IU Cinquima-Quimica Inorgánica, Faculty of Science, University of Valladolid, Campus Miguel Delibes, Paseo de Belén 7, 47011 Valladolid, Spain; 이이.org/0000-0002-3230-3802
Miguel A. Rodríguez-Pérez - Cellular Materials Laboratory (CellMat), Condensed Matter Physics Department, Faculty of Science, University of Valladolid, 47011 Valladolid, Spain; Present Address: Cellular Materials Laboratory (CellMat), Condensed Matter Physics Department, Faculty of Science, University of Valladolid, Campus Miguel Delibes, Paseo de Belén 7, 47011 Valladolid, Spain.; Present Address: BioEcoUVA Research Institute on Bioeconomy, University of Valladolid, 47011 Valladolid, Spain.

Complete contact information is available at: https://pubs.acs.org/10.1021/acsapm.1c00712

\section{Author Contributions}

This manuscript was written through the contributions of all authors. All authors have given approval to the final version of the manuscript.

\section{Notes}

The authors declare no competing financial interest.

\section{ACKNOWLEDGMENTS}

Financial support was received from the FPU grant FPU17/ 03299 (Beatriz Merillas) from the Ministerio de Ciencia, Innovación y Universidades (RTI2018-098749-B-I00). Financial assistance was received from the Junta de Castilla y León (VA202P20) and the "Ente Público Regional de la Energía de Castilla y León” (EREN). The authors would like to thank Alberto Santiago Aliste, from the Unidad de Microscopía of the Parque Científico of the University of Valladolid, for the HR-SEM measurements. The authors would also like to thank María Dolores Marqués Gutiérrez, from the Porous Solids Laboratory of the University of Malaga, for the nitrogen adsorption measurements.

\section{REFERENCES}

(1) Maleki, H.; Durães, L.; García-González, C. A.; del Gaudio, P.; Portugal, A.; Mahmoudi, M. Synthesis and Biomedical Applications of Aerogels: Possibilities and Challenges. Adv. Colloid Interface Sci. 2016, $236,1-27$.

(2) Bheekhun, N.; Rahim, A.; Talib, A.; Hassan, M. R. Aerogels in Aerospace: A Review. Adv. Mater. Sci. Eng. 2013, 2013, 1-18. 
(3) Yu, C. H.; Fu, Q. J.; Tsang, S. C. E. Aerogel Materials for Insulation in Buildings. Mater. Energy Effic. Therm. Comf. Build. 2010, 319-344.

(4) Ganobjak, M.; Brunner, S.; Wernery, J. Aerogel Materials for Heritage Buildings: Materials, Properties and Case Studies. J. Cult. Heritage 2020, 42, 81-98.

(5) Li, C.; Chen, Z.; Dong, W.; Lin, L.; Zhu, X.; Liu, Q.; Zhang, Y.; Zhai, N.; Zhou, Z.; Wang, Y.; Chen, B.; Ji, Y.; Chen, X.; Xu, X.; Yang, Y.; Zhang, H. A Review of Silicon-Based Aerogel Thermal Insulation Materials: Performance Optimization through Composition and Microstructure. J. Non-Cryst. Solids 2021, 553, No. 120517.

(6) Günay, A. A.; Kim, H.; Nagarajan, N.; Lopez, M.; Kantharaj, R.; Alsaati, A.; Marconnet, A.; Lenert, A.; Miljkovic, N. Optically Transparent Thermally Insulating Silica Aerogels for Solar Thermal Insulation. ACS Appl. Mater. Interfaces 2018, 10, 12603-12611.

(7) Carraher, C. E. Silica Aerogels - Properties and Uses. Polym. News 2005, 30, 386-388.

(8) Maleki, H.; Durães, L.; Portugal, A. An Overview on Silica Aerogels Synthesis and Different Mechanical Reinforcing Strategies. J. Non-Cryst. Solids 2014, 385, 55-74.

(9) Goetzberger, A. Potential Uses of Transparent Insulation Materials for Thermal Collectors and in Buildings. Sol. Wind Technol. 1987, 4, 389-393.

(10) McEnaney, K.; Weinstein, L.; Kraemer, D.; Ghasemi, H.; Chen, G. Aerogel-Based Solar Thermal Receivers. Nano Energy 2017, 40, $180-186$.

(11) Butts, D. M.; McNeil, P. E.; Marszewski, M.; Lan, E.; Galy, T.; Li, M.; Kang, J. S.; Ashby, D.; King, S.; Tolbert, S. H.; Hu, Y.; Pilon, L.; Dunn, B. S. Engineering Mesoporous Silica for Superior Optical and Thermal Properties. MRS Energy Sustainability 2020, 7, 1-12.

(12) Aegerter, M. A.; Leventis, N.; Koebel, M. Aerogels Handbook; Springer: USA, 2011.

(13) Svendsen, S. Solar Collector with Monolithic Silica Aerogel. J. Non-Cryst. Solids 1992, 145, 240-243.

(14) Hrubesh, L. W.; Poco, J. F. Thin Aerogel Films for Optical, Thermal, Acoustic and Electronic Applications. J. Non-Cryst. Solids 1995, 188, 46-53.

(15) Reim, M.; Beck, A.; Körner, W.; Petricevic, R.; Glora, M.; Weth, M.; Schliermann, T.; Fricke, J.; Schmidt, C.; Pötter, F. J. Highly Insulating Aerogel Glazing for Solar Energy Usage. Sol. Energy 2002, $72,21-29$.

(16) Duer, K.; Svendsen, S. Monolithic Silica Aerogel in Superinsulating Glazings. Sol. Energy 1998, 63, 259-267.

(17) Buratti, C.; Belloni, E.; Merli, F.; Zinzi, M. Aerogel Glazing Systems for Building Applications: A Review. Energy Build. 2021, 231, No. 110587

(18) Huang, Y.; Niu, J. lei. Application of Super-Insulating Translucent Silica Aerogel Glazing System on Commercial Building Envelope of Humid Subtropical Climates - Impact on Space Cooling Load. Energy 2015, 83, 316-325.

(19) Vivod, S. L.; Meador, M. A. B.; Pugh, C.; Wilkosz, M.; Calomino, K.; McCorkle, L. Toward Improved Optical Transparency of Polyimide Aerogels. ACS Appl. Mater. Interfaces 2020, 12, 86228633.

(20) Smalyukh, I. I. Thermal Management by Engineering the Alignment of Nanocellulose. Adv. Mater. 2020, 33, No. 2001228.

(21) Liu, Q.; Frazier, A. W.; Zhao, X.; De La Cruz, J. A.; Hess, A. J.; Yang, R.; Smalyukh, I. I. Flexible Transparent Aerogels as Window Retrofitting Films and Optical Elements with Tunable Birefringence. Nano Energy 2018, 48, 266-274.

(22) Mi, Q. Y.; Ma, S. R.; Yu, J.; He, J. S.; Zhang, J. Flexible and Transparent Cellulose Aerogels with Uniform Nanoporous Structure by a Controlled Regeneration Process. ACS Sustainable Chem. Eng. 2016, 4, 656-660.

(23) Kobayashi, Y.; Saito, T.; Isogai, A. Aerogels with 3D Ordered Nanofiber Skeletons of Liquid-Crystalline Nanocellulose Derivatives as Tough and Transparent Insulators. Angew. Chem., Int. Ed. 2014, 53, 10394-10397.
(24) Nakanishi, Y.; Hara, Y.; Sakuma, W.; Saito, T.; Nakanishi, K.; Kanamori, K. Colorless Transparent Melamine-Formaldehyde Aerogels for Thermal Insulation. ACS Appl. Nano Mater. 2020, 3, 49-54.

(25) Takeshita, S.; Zhao, S.; Malfait, W. J. Transparent, AldehydeFree Chitosan Aerogel. Carbohydr. Polym. 2021, 251, No. 117089.

(26) Riffat, S. B.; Qiu, G. A Review of State-of-the-Art Aerogel Applications in Buildings. Int. J. Low-Carbon Technol. 2013, 8, 1-6.

(27) Burgaz, E. Polyurethane Insulation Foams for Energy and Sustainability 2019, Vol. 111.

(28) Hickel, R. Directive 2010/31/EU of the European Parliament and of the Council on the Energy Performance of Buildings. Presse Med. 1955, 63, 619.

(29) Biesmans, G.; Randall, D.; Francais, E.; Perrut, M. Polyurethane-Based Organic Aerogels' Thermal Performance. J. Non-Cryst. Solids 1998, 225, 36-40.

(30) Biesmans, G. Polyurethane Based Organic Aerogels and Their Transformation into Carbon Aerogels. J. Non-Cryst. Solids 1998, 225, 64-68.

(31) Rigacci, A.; Marechal, J. C.; Repoux, M.; Moreno, M.; Achard, P. Preparation of Polyurethane-Based Aerogels and Xerogels for Thermal Superinsulation. J. Non-Cryst. Solids 2004, 350, 372-378.

(32) Diascorn, N.; Calas, S.; Sallée, H.; Achard, P.; Rigacci, A. Polyurethane Aerogels Synthesis for Thermal Insulation - Textural, Thermal and Mechanical Properties. J. Supercrit. Fluids 2015, 106, 76-84.

(33) Chidambareswarapattar, C.; Mccarver, P. M.; Luo, H.; Lu, H.; Sotiriou-leventis, C.; Leventis, N. Fractal Multiscale Nanoporous Polyurethanes: Flexible to Extremely Rigid Aerogels from Multifunctional Small Molecules. Chem. Mater. 2013, 25, 3205-3224.

(34) Zhu, Z.; Snellings, G. M. B. F.; Koebel, M. M.; Malfait, W. J. Superinsulating Polyisocyanate Based Aerogels: A Targeted Search for the Optimum Solvent System. ACS Appl. Mater. Interfaces 2017, 9, $18222-18230$.

(35) Riffat, S. B.; Qiu, G. A Review of State-of-the-Art Aerogel Applications in Buildings. Int. J. Low-Carbon Technol. 2013, 8, 1-6.

(36) Kamiuto, K.; Miyamoto, T.; Saitoh, S. Thermal Characteristics of a Solar Tank with Aerogel Surface Insulation. Appl. Energy 1999, 62, 113-123.

(37) ASTM D1622-08: Standard Test Method for Apparent Density of Rigid Cellular Plastics.

(38) Barrett, E. P.; Joyner, L. G.; Halenda, P. P. The Determination of Pore Volume and Area Distributions in Porous Substances. I. Computations from Nitrogen Isotherms. J. Am. Chem. Soc. 1951, 73, 373-380.

(39) Pinto, J.; Solórzano, E.; Rodriguez-Perez, M. A.; De Saja, J. A. Characterization of the Cellular Structure Based on User-Interactive Image Analysis Procedures. J. Cell. Plast. 2013, 49, 555-575.

(40) Schwetlick, K.; Noack, R. Kinetics and Catalysis of Consecutive Isocyanate Reactions. Formation of Carbamates, Allophanates and Lsocyanurates. J. Chem. Soc., Perkin Trans. 2 1995, 2, 395-402.

(41) Technical Information KOSMOS 75 MEG, GmbH, Evonik Nutrition \& Care.

(42) Rewatkar, P. M.; Saeed, A. M.; Majedi Far, H.; Donthula, S.; Sotiriou-Leventis, C.; Leventis, N. Polyurethane Aerogels Based on Cyclodextrins: High-Capacity Desiccants Regenerated at Room Temperature by Reducing the Relative Humidity of the Environment. ACS Appl. Mater. Interfaces 2019, 11, 34292-34304.

(43) Romero, R. R.; Grigsby, R. A.; Rister, E. L.; Pratt, J. K.; Ridgway, D. A Study of the Reaction Kinetics of Polyisocyanurate Foam Formulations Using Real-Time FTIR. J. Cell. Plast. 2005, 41, 339-359.

(44) Pirard, R.; Rigacci, A.; Maréchal, J. C.; Quenard, D.; Chevalier, B.; Achard, P.; Pirard, J. P. Characterization of Hyperporous Polyurethane-Based Gels by Non-Intrusive Mercury Porosimetry. Polymer 2003, 44, 4881-4887.

(45) Thommes, M.; Kaneko, K.; Neimark, A. V.; Olivier, J. P.; Rodriguez-reinoso, F.; Rouquerol, J.; Sing, K. S. W. Physisorption of Gases, with Special Reference to the Evaluation of Surface Area and Pore 
Size Distribution (IUPAC Technical Report), 2015. https://doi.org/10. 1515/pac-2014-1117.

(46) Venkateswara Rao, A.; Pajonk, G. M. Effect of Methyltrimethoxysilane as a Co-Precursor on the Optical Properties of Silica Aerogels. J. Non-Cryst. Solids 2001, 285, 202-209.

(47) Takeshita, S.; Yoda, S. Chitosan Aerogels: Transparent, Flexible Thermal Insulators. Chem. Mater. 2015, 27, 7569-7572.

(48) Ayadi, F.; Martín-García, B.; Colombo, M.; Polovitsyn, A.; Scarpellini, A.; Ceseracciu, L.; Moreels, I.; Athanassiou, A. Mechanically Flexible and Optically Transparent Three-Dimensional Nanofibrous Amorphous Aerocellulose. Carbohydr. Polym. 2016, 149, 217-223.

(49) Pajonk, G. M. Transparent Silica Aerogels. J. Non-Cryst. Solids 1998, 225, 307-314.

(50) Wang, J.; Petit, D.; Ren, S. Transparent Thermal Insulation Silica Aerogels. Nanoscale Adv. 2020, 2, 5504-5515.

(51) Cao, W.; Hunt, A. J. Improving the Visible Transparency of Silica Aerogels. J. Non-Cryst. Solids 1994, 176, 18-25.

(52) Martín-de León, J.; Pura, J. L.; Bernardo, V.; Rodríguez-Pérez, M. Á. Transparent Nanocellular PMMA: Characterization and Modeling of the Optical Properties. Polymer 2019, 170, 16-23. 